\title{
Orofacial Impactions: A Common Rarity
}

\author{
${ }^{1}$ Freny Karjodkar, ${ }^{2}$ S unali Khanna, ${ }^{1}$ Darshana Patil \\ ${ }^{1}$ P rofessor, Department of Oral Medicine and Radiology, Nair Hospital Dental College, Mumbai, Maharashtra, India \\ ${ }^{2}$ Assistant Professor, Department of Oral Medicine and Radiology, Nair Hospital Dental College, Mumbai, Maharashtra, India
}

\begin{abstract}
Correspondence: Sunali Khanna, Assistant P rofessor, Department of Oral Medicine and Radiology, Nair Hospital Dental College
\end{abstract} Mumbai-400008, Maharashtra, India, e-mail: sunalikhanna@ gmail.com

\section{ABSTRACT}

Impactions of the orofacial region are rare but impactions of the mobile tongue are unique. Hence, very limited literature is available. Foreign bodies embedded in the maxillofacial region frequently result from trauma and dental treatment. This is a compilation of cases of tongue impaction, tooth in maxillary sinus and watch battery impacted in tooth. A brief insight into the incidence of orofacial impactions, radiographic investigations and management is also provided.

Keywords: Tongue, Impaction, Maxillary sinus, Tooth.

\section{INTRODUCTION}

Impactions in the maxillofacial region are a challenging task to diagnose. According to Dorland's medical dictionary, foreign body is defined as 'a mass or particle of material which is not normal to the place where it is found'. ${ }^{1}$

Foreign bodies include a vast majority of objects. Fish bones constitute about $85 \%$ of all foreign bodies. M etallic fillings, fragments of wood, broken needles and broken instruments are examples of foreign body lodgments. The tooth fragments, bone parts, and so on get impacted into oral soft tissues either accidently during surgical procedure or due to trauma. There are cases reported of inlay in tongue with inflammatory reaction of surrounding bone and fish bone penetrating the anterior tongue. ${ }^{2,3}$ Interesting cases of blue pen cap with a surrounding pneumocele at the floor of the mouth and migrating foreign body in tongue leads to complications, such as ecchymosis, small lumps, submental swelling and neuralgic type pain., ${ }^{4,5}$ Review of literature indicates lodgment of a T-shaped metal object from an umbrella in the tongue of a 4-year-old child that was operated using intraoperative fluoroscopy radiography. ${ }^{6}$ Cases of autologous foreign body (tooth) and fish bone impaction along with granuloma formation in the tongue are also documented. ${ }^{7,8}$

\section{CASE REPORTS}

\section{Case 1}

A 25-year-old patient reported to our institute with pain, dysphagia, dysarthria since past few months. On examination, a well-defined swelling of size of approximately $1.5 \mathrm{~cm}$ was observed on ventral surface of tongue. There was a history of road traffic accident 5 years back. A chunk of calculus was clinically visible (Fig. 1). Surrounding tissue was inflamed and bleeding on slight provocation was evident. Due to longer duration of trauma, dense granulation tissue was present and calculus deposition was significant due to close vicinity of submandibular and sublingual duct orifices. To investigate, an orthopantomograph was taken and a radiopacity resembling a tooth structure in the interincisal area was evident (Fig. 2). Bilateral lingual nerve block and lingual infiltration were given. The granulation tissue was sheared and a tooth was recovered on surgical exploration (Fig. 3). From the clinical and radiographic examinations we came to the conclusion that the tooth was mandibular left lateral incisor which got impacted at the ventral surface of tongue because of trauma. In this case, main concern was to tackle with profuse bleeding as the tooth was deep in the tongue tissue and was in close vicinity with the lingual veins.

\section{Case 2}

A 22-year-old patient with swelling over the infraorbital region along with pus discharge from upper right third molar region since last 2 years and fever reported to our institute. The extra oral swelling was tender on pal pation. To diagnose the case PA W aters and OPG were taken. PA W aters showed an impacted maxillary right third molar near medial border of right maxillary sinus. On the contrary, OPG was showing same tooth close to the lateral border. This dilemma was solved by CT findings which were showing that the tooth was localized close to the medial wall of the sinus with its 


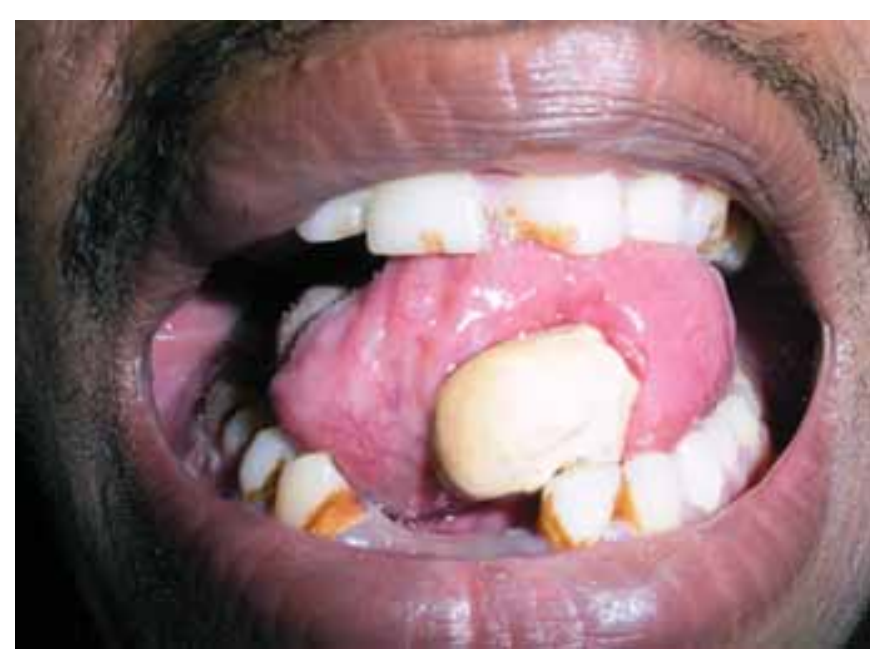

Fig. 1: Calculus and swelling at the ventral surface of tongue

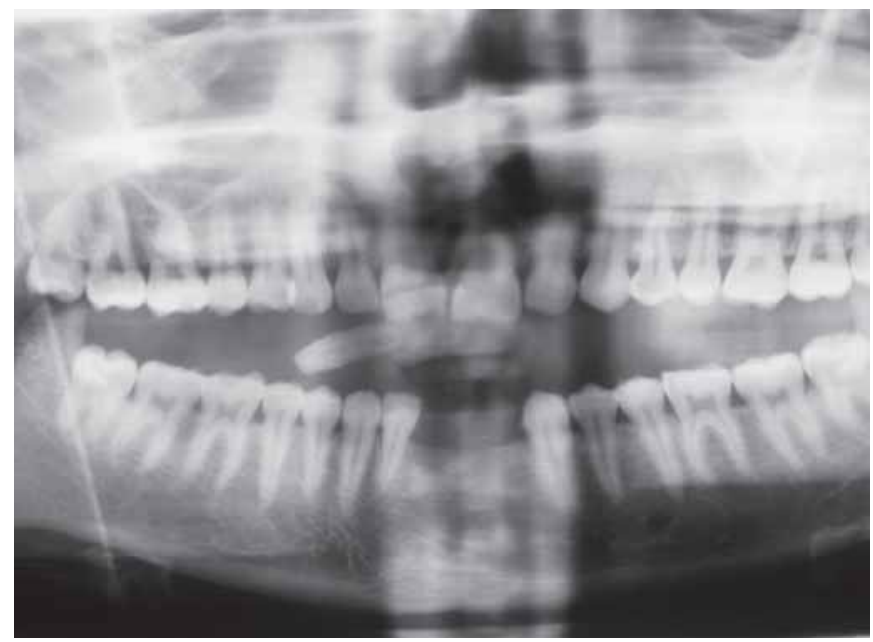

Fig. 2: Orthopantomograph (OPG) shows tooth-like radiopacity in the proximity to mandibular anteriors

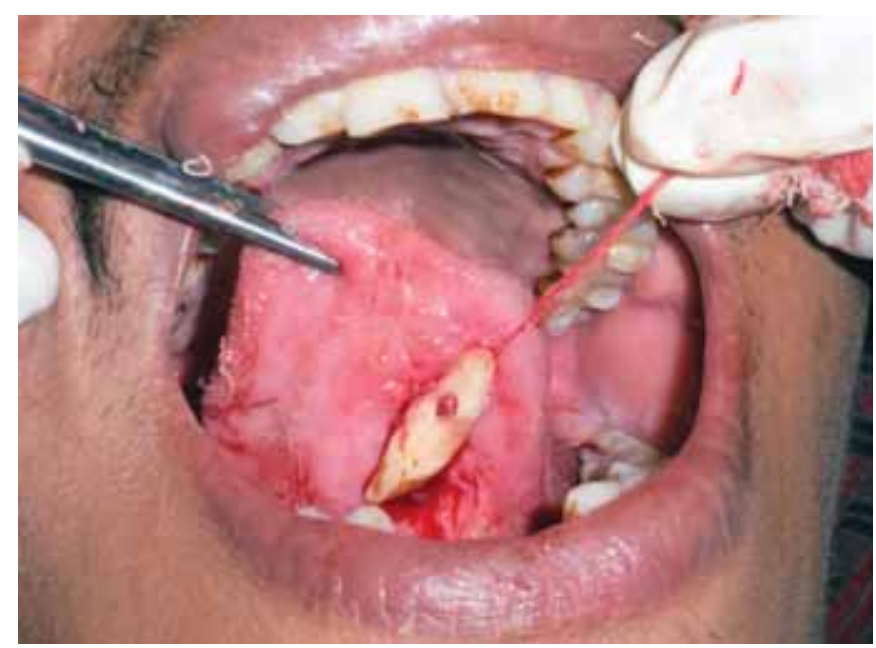

Fig. 3: Surgical exploration reveals tooth embedded in tongue

roots medially and crow $n$ directing distally, quite a distance from the superior and inferior borders with a cystic lesion in relation to it(Fig. 4). The tooth was removed by antroscopy.

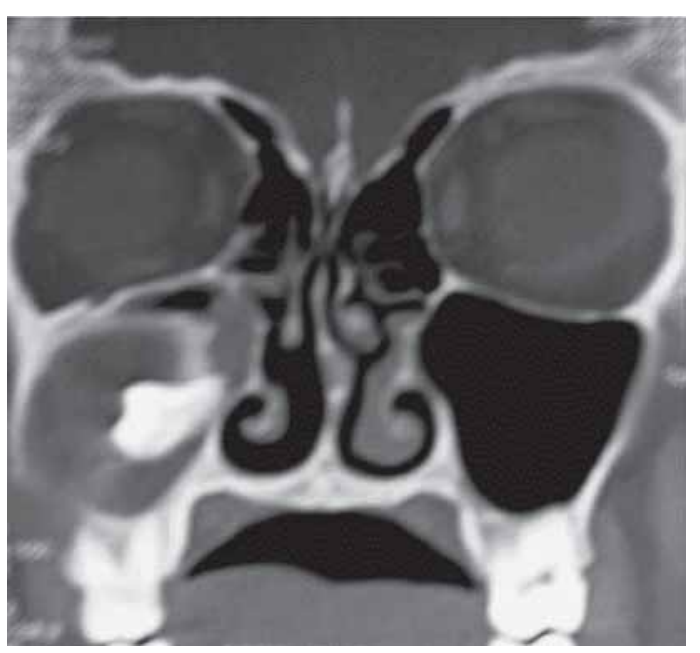

Fig. 4: Computed tomography (CT) scan (coronal section) reveals tooth in right maxillary sinus

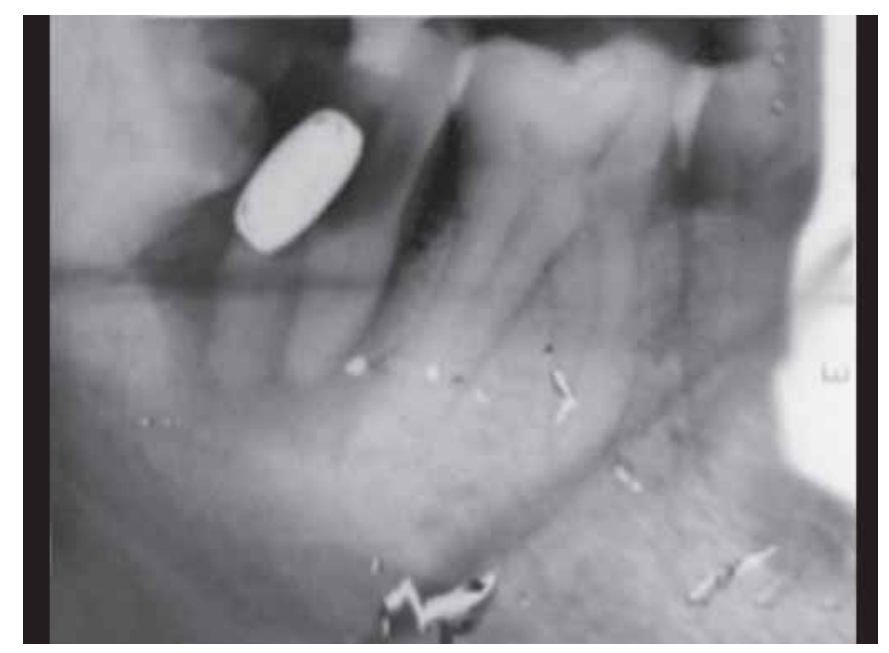

Fig. 5: IOPA shows oval radiopacity with respect to 17

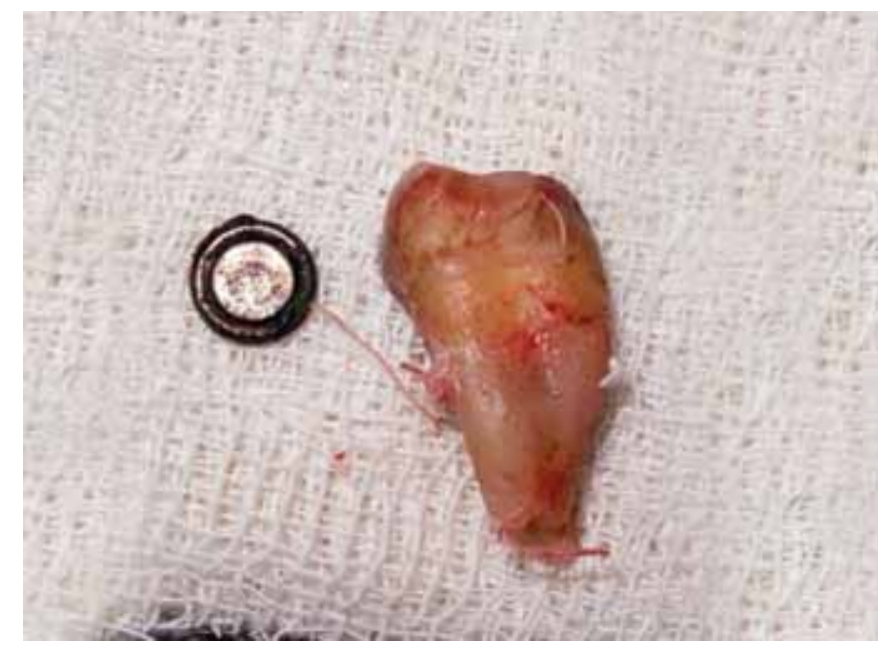

Fig. 6: Extracted 17 along with watch battery

A nother interesting case came to our institute in which a 40 years old male patient reported with the complaint of pain in lower left posterior teeth region. Patient was working 
in watch factory and was giving history of forceful lodgment of watch battery in the tooth while working.

Submandibular lymph nodes of left side were palpable, tender and mobile. On intraoral examination, a round watch battery that was embedded in the proximal surface of grossly carious mandibular left second molar (Fig. 5). An IOPA was taken which showed grossly carious mandibular left second molar with periapical rarefaction. A radiopaque material was seen in the distal area of the tooth that was suggestive of foreign body (watch battery). In this patient, the infected mandibular left second molar was extracted. The watch battery came out of the oral cavity along with extracted tooth (Fig. 6).

\section{DISCUSSION AND CONCLUSION}

Foreign body impaction is very common in children as well as in adults. Fish bones are the most commonly reported foreign bodies (85\%). Most of the patients are giving the history of accidental swallowing of the foreign body which can also be homicidal or suicidal. Most common foreign bodies in children are coins, marbles, buttons, batteries, bottle tops. In adults fish bones, dentures and metallic wires are noted commonly. ${ }^{9} \mathrm{~A}$ majority of the foreign bodies are impacted in tonsils, base of tongue, maxillary sinus and vallecula. ${ }^{10}$ Foreign bodies in mobile tongue are, however, rare. It has been seen that a foreign body can migrate through the deeper submucosal and mucosal layers that will make the diagnoses difficult. Foreign body reaction can occur that will result in formation of granuloma or an abscess.

$M$ ain dilemma lies in the fact that the foreign bodies are difficult to diagnose and localize. Localization imaging techniques are essential to conform the presence and location of the foreign body. Simple radiographs are routinely used for this purpose. Whenever it is possible, two radiographs should be made at right angles to one another. This method is very helpful when removal of foreign body is to be done and palpation or visualization cannot detect the object. ${ }^{1}$ Triangulation is one of the best method to local ize the object accurately, provided appropriate equipments are present. ${ }^{1}$ When simple radiographs cannot localize the objects, specialized methods such as CT, MRI, ultrasonography, positron emission tomography (PET) can be used. UItrasonography detects and localizes superficial foreign bodies with low radiopacity in the tissues of the body more effectively than $\mathrm{CT}$ and conventional plain radiography. However, CT is more effective for visualization of foreign bodies in air than ultrasound and conventional plain radiography.

As the tongue is a mobile organ in relation to the bony landmarks, intraoperative clinical judgment plays a pivotal role in approaching the object. M oreover, as surgical exploration usually remains the only choice, accurate object localization is imperative. Perioperative steroid administration is hel pful in reducing the tongueedema. A lthough the tongue is subjected to constant trauma, inflammatory conditions due to trauma are rare. This can be attributed to high vascularity, unique muscular anatomy, thickness of covering mucosa and the cleansing action of saliva. Once the mechanical barrier of tongue mucosa is breached, infections could be severe. Foreign bodies embedded in mobile tongue form an important differential diagnosis in the cases presenting with atypical pain or lumpand sw elling of tongue.

\section{REFERENCES}

1. Worth HM . A nomalies of eruption; retained roots: A nkylosis of teeth; foreign Bodies. Principles and Practice of Oral Radiographic Interpretation (3rd Ed). Y ear Book Medical Publishers Inc. Chapter no.5 1972;207-08.

2. Sayari K, Y okobayashi $Y$, Hideshima Y. Foreign body in the tongue (inlay). A case report. J apanese J of O ral and M ax Surg 2000;46:811-13.

3. Kalpesh P. Foreign body in the tongue: A $n$ unusual site for a common problem. J Laryngology and Otology 1991;105: 849-50.

4. Zafer U guz M, Kazikdas K, et al. U nusual foreign body in the floor of mouth presenting as gradually growing mass. European A rchives of Otorhinolaryngology 2005;262:875-77.

5. Breik 0, Hay HD. Migrating foreign bodies in the tongue. Newzealand Dent J 2008;104(2):62-69.

6. De Silva EJ, Deng Y, Tumushime-Buturo CG. A n unusual foreign body in the tongue. $\mathrm{Br}$ J of Oral and M axillofac Surg 2000;38:241-42.

7. Rohit V, Kapil S, Thakkar A. A utologous embedded foreign body of mobile tongue. Indian J of Otolaryngology and Head and Neck Surg 2007;59:291-92.

8. Lin Chao-Jung, Su W an-Fu, Wang Chi-Hung. A foreign body embedded in the mobile tongue masquerading as neoplasm. Euro A rchives of Otorhinolaryngology 2003;260:277-79.

9. Shivakumar A, A shok N, Prashant K, Girish H, Gaurav C. Foreign body in upper digestive tract. Indian J of Otolaryngology and head and neck surg 2006;71:689-93.

10. Leong HK, Chan RK. Foreign bodies in the upper digestive tract. Singapore M ed J 1987;28:162-65. 


\section{Editorial Inputs}

\section{Orofacial Impactions: A Common Rarity}

\section{Abhoya Kumar Kar}

President IMA, Orissa, Central Council Member, IMA HQs, New Delhi, India Editorial Chairman,O rissa J ournal of Otolaryngology and Head and Neck Surgery Honorary Visiting Professor, Annamalai University, Tamil Nadu, India

Editorial Board Member, World Articles in ENT, ORL Clinics International J ournal and Indian J ournal of Clinical Medicine

Retd. Head, PG, Department of ENT, MKCG Medical College, Berhampur and GSL Medical College, Rajahmundry, Andhra Pradesh, India

\section{CASE REPORTS}

\section{Case 1}

A boy aged 9 years (1984) was playing in a building under construction with his friends. He fell down a floor and an exposed iron rod of a pillar pierced through his left nostril and came out below the left eye ball. The village doctor tried to remove it, but could not as the rod was curved and bent at the tip. The villagers cut the rod in an eratic way, longer than the height of the boy.

The boy was admitted in the Casuality.

On X-ray of head PA and lat view, it was seen that, the iron rod had entered the maxillary sinus through the medial wall and the exit was through the roof. Then it had pierced the inferior conjuctiva and had come out in between left eye ball and lower eye lid. But pecurarily the vision was normal.

A $n$ ophthalmic surgeon was called and under general anesthesia with endotracheal intubation, the iron rod was removed in the reverse route of the route of entry by gentle manipulation. The gap in conjuctiva and medial wall of maxillary sinus was repaired. A $n$ intranasal antrostomy was done and the maxillary sinus was packed with antibiotic soaked ribbon gauze, which was removed after 48 hours.

\section{Case 2}

In 1986, a girl aged 4 years was admitted in emergency with history of swallowing a 50 paise coin 48 hours back. The foreign body was not expelled through feces. There was no difficulty in respiration and deglutition.

On plain X-ray of neck, chest and abdomen (PA and lat views) and Barium swallow screening of alimentary tract, the foreign body was not visualized.

Then I advised for X -ray of nasopharynx (A P and lateral views). The 50 paise coin was seen in the roof of nasopharynx sticking to the adenoid mass, which was removed under general anesthesia with endotracheal intubation, after dislodging the FB from the adenoid.

So when aforeign body can notbetraced, routineskiagram of the nasopharynx should be carried out. 